\title{
Aproximación a Vírgenes del Sol Inn Cabaret...: una condición Posthistórica y de Competencia Literaria
}

\section{Approach to Virgenes del Sol inn Cabaret ...: a Post-historic Condition and Literary Competence}

\section{Resumen}

Este análisis ${ }^{1}$ tiene por objeto plantear una aproximación teórico-crítico-literaria y desde un linde posthistórico ${ }^{2}$ de la obra poética Vírgenes del Sol Inn Cabaret: vien benidos a la máquina welcome to the tv de Alexis Figueroa (1986). Este acercamiento nos lleva a comprender su producción desde tres claves: endoculturación, competencia literaria y endotextualidad. Todas ellas dan cuenta del entramado cultural en el cual están inmersos, escritor y/o lector, y se han de encontrar en la obra, que más bien, es una síntesis endotextual de la endoculturación y la competencia literaria.

Palabras claves

Posthistoria, endotextualidad, Alexis Figueroa, neovanguardia chilena

${ }^{1}$ Corresponde a una ponencia presentada en el "XX Congreso Internacional SOCHEL, Figuras de lo Común: Formas y Disensos en los Estudios Literarios (Lenguas, Cuerpos, Sentidos y Escrituras). PUCV. Valparaíso-Chile.

${ }^{2}$ Aproximación conceptual realizada en un libro de mi coautoría con la Dra Edith Cerda Osses titulado Condición Posthistórica o manifestación poliexpresiva... Una perturbación sensible. 2019. En edición. 


\section{Abstract}

The purpose of this analysis is to propose a theoretical-critical-literary approach and from a post-historical edge to the poetic work Vírgenes del Sol Inn Cabaret: vien benidos a la máquina welcome to the tv by Alexis Figueroa (1986). This approach leads us to understand its production from three keys: endoculturation, literary competence and endotextuality. All of them give an account of the cultural framework in which they are immersed, writer and / or reader, and must be found in the work, which is rather an endotextual synthesis of endoculturation and literary competence.

Keywords

Post-history, endotextuality, Alexis Figueroa, Chilean neo-avant-garde

\section{UNA COMO CONDICIÓN POSTHISTÓRICA...}

1.1. Para poder aproximarnos a 'una como condición posthistórica', habría que hacerlo pensando en que "el momento histórico es constitutivo de las obras de arte" (Adorno 241) ya que:

Son auténticas aquellas que, sin reticencias y sin creerse que están sobre él, cargan con el contenido histórico de su tiempo. Son la historia de su época, pero inconsciente de sí misma; esto las convierte en mediaciones del conocimiento. [...] las obras de arte pueden experimentarse con tanta más verdad cuanto más coincide su sustancia histórica con la del que la experimenta. (Ibidem)

Por lo tanto, este acercamiento propuesto ha de ser:

desde una teoría-crítica-literaria; la que me daría herramientas de interpretación o cualificación del hecho estético en su total dimensión. No solo desde la teoría literaria y sus asuntos, sino que desde la historia en que se sitúa el autor (sin ser biográfico ni psicológico ni sociológico) con toda su constelación (como diría Adorno). Por lo tanto, la visión de mundo del autor no solo se corresponde con la idea literaria y con los recursos 
literarios, sino que se complementa con un mapa cognitivo que es su propia época. (Rosas La nueva novela 12)

De tal manera que, con este acercamiento en general, por ahora, podemos dar cuenta, en estos últimos años, de una suerte de entropía en el arte, es decir, una cantidad posible de mensajes y de los cuales solo se puede emitir uno. Y esta, medio que incertidumbre cultural e histórica y medio que indiscernibilidad, es la "entropía estética" (Danto 32). Pero al mismo tiempo "nos encontraríamos con la sensación de que no tenemos un estilo identificable, que no hay nada que no se adapte a él. Pero eso es lo que caracteriza a las artes visuales desde el fin del modernismo, [...] y no hay en consecuencia una posible directriz" (34). Y por lo tanto tampoco podemos discernir bien los límites del arte y por ello entonces, siguiendo los planteamientos dantonianos, se estaría viviendo en una época en la que estaría claro que el arte pudiera estar hecho de cualquier cosa, y donde no hubiera ninguna marca por la cual las obras de arte pudieran ser perceptualmente diferenciadas de los objetos más ordinarios. Y esto, ciertamente nos colocaría frente a la idea, o más bien, a la prueba del cierre o clausura de la Historia, pues se habría alcanzado la autoconciencia y consiguientemente habría surgido una nueva realidad en la que no habría un estilo contemporáneo ni habría formas discernibles en el arte, por lo tanto, se ha iniciado la posthistoria, entendida esta, desde el supuesto que: "ahora que al menos ha sido alcanzada la visión de una autoconciencia, esa historia ha concluido. Se ha liberado a sí misma de una carga que podrá entregar a los filósofos. Entonces los artistas [...] fueron libres para hacer arte en cualquier sentido que desearan, con cualquier propósito que desearan o sin ninguno" (37). En suma, estaríamos más próximos a una apropiación de mundo que a una visión de mundo, ya que "Danto considera que los relatos del arte actual han llegado a su fin, pues ya no es posible ninguna narrativa, iniciándose de esta manera la post-historia del arte encarnada en el arte contemporáneo" (Vásquez Rocca, párr.: 07). 


\subsection{Hacia una endoculturación}

En el arte literario actual, entonces, no solo se daría cita el sujeto lírico, sino que el cultural e histórico también. Ya que están en constante búsqueda entre la asimilación cultural, más bien contracultural y la expresividad simbólica. Es decir, que esta necesidad de búsqueda y de apropiación de mundo, rastreada y pesquisada en el sujeto histórico, como contra respuesta del sujeto espiritual, el artista; lo que se definiría o traduciría endoculturalmente (Harris), como aquello que se relacionaría con una experiencia de aprendizaje parcialmente consciente y parcialmente inconsciente a través de la cual, la generación de más edad; incita, induce y obliga a la generación más joven a adoptar los modos de pensar y comportarse tradicionales. Todo ello para que se mantuviese una continuidad, que se evidenciara en los estilos de vida en que se ampararan gracias al proceso conocido como endoculturación. Y más todavía, cuando:

El arte siempre representa alguna cosa - comunica una información-, pero esta cosa nunca es representada en su forma, sonido, color, movimiento o sentimiento literales. A diferencia de lo que ocurre en otras formas de comunicación, la representación, para ser arte, debe transformarse en algún tipo de expresión lingüística, movimiento, imagen u objeto metafóricos o simbólicos que están en lugar de lo que está siendo representado. (Harris 392)

Lo que se explicaría entonces, según el antropólogo, como que el arte hace uso de varios ingredientes, los que serían clave para una mejor comprensión de este, y que contemplaría, según la definición de Alexander Alland: «juego», «forma», «estética»y «transformación» revisada por el mismo Harris: "El juego es un aspecto agradable y gratificante de la actividad que no cabe explicar sencillamente por sus funciones utilitarias o de supervivencia. La forma designa un conjunto de restricciones que afectan a la organización espacial y temporal del juego artístico: 
las reglas del juego del arte" (391). Ciertamente, como lo avala el diligente autor en el epígrafe del capítulo referido a "El arte": "Veremos que el arte no es un sector aislado de la experiencia humana; está íntimamente relacionado con otros aspectos de los sistemas socioculturales" (391).

Y esto es, en términos generales, en el análisis que nos ocupa, una relación íntima del entramado cultural, más bien, endocultural, o sea que, siguiendo esta lógica, una endotextualidad ${ }^{3}$, ya que en este nueva textualidad, "la profundización va más allá de la página, se expande a la propia vida, enriqueciendo las respuestas a los estímulos externos a la hora de reaccionar ante todo el espectro de experiencias humanas" (Brierley 114), sea ésta como producción o recepción. También, de este modo la profundización, se convierte en actualización del tiempo y el espacio en que se vive. O sea, se establece como una suerte de continuidad crítica de la Historia Moderna o Modernidad. En definitiva, se percibe como un agotamiento del relato o metarrelato o, al menos como una condición de agotamiento que nos acerca a la posthistoria.

\subsection{Condición de agotamiento...}

Sin embargo, creemos que la Modernidad solo sigue en crisis y esta sería la condición posmoderna que nos hace sentir y asociar de inmediato el Fin de la Historia. Primero, como el resultado de la fusión de tres factores:

la idea nietzscheana del agotamiento espiritual del repertorio de posibilidades heroicas, la tesis weberiana de una sociedad convertida en

\footnotetext{
${ }^{3}$ Aquí, en realidad estoy pensando en la superación de la sola fenomenología y genealogía del texto, es decir, aquí se concilia la vida cultural individual y colectiva del autor como la del lector. Se conjuga, finalmente, la Competencia Literaria. Entonces el endotexto hace justicia al proceso de internalización de todo texto (feno) y tejido cultural (geno), lo que estéticamente se ha llamado "apropiación de mundo". Y este constructo asimilado como realidad se expresa en un texto, de cualquier tipo y de cualquier forma; lo que se ha llamado hasta ahora simbolización y en mis planteamientos: poliexpresión. Ello, a diferencia del término kristeviano de genotexto que se separa del fenotexto (Julia Kristeva "La sémiotique" 280-283).
} 
una única máquina gigantesca en proceso de petrificación y la hipótesis de Henry Adams de una entropía en el proceso de cambio de civilización. (López-Dominguez 1999 306)

Y segundo, como "sacralizando el capitalismo y anteponiendo el criterio del éxito histórico por encima de cualquier otro" (307).

Ahora bien, este agotamiento espiritual, petrificación y entropía se revelaría entonces, mediante la sacralización capitalista y la simbolización, como herramienta antropológica de la manifestación del lenguaje $\mathrm{e}^{4}$ que supera toda reductividad lingüística y que es, más bien, capaz de organizarse sobre la base de una codificación mayor o, transcodificación, que conlleva la intención de expresar el mundo, sacudiéndose el agotamiento espiritual a través de la expresión. De manera que, esta transcodificación, obedece simultáneamente a la necesidad de expresarse como sujeto activo, movilizando con dificultad la petrificación y la entropía, ya sea de modo cultural o lírico y, por lo tanto el contexto, que no solo depende del texto como producto, sino que también del texto como recepción, ya que el sujeto cultural, todo él, con su constelación a cuestas, es el que recibe o evidencia esta internalización en/con/del/ texto como condición posmoderna, en realidad posthistórica de agotamiento espiritual, petrificación y entropía, en que vivimos. De modo tal, que esta internalización o crisis, vamos a entenderla como un impulsor y regulador de vivencia y aprehensión del mundo (endoculturalidad) y como recepción y expresión de la vivencia de signos (simbolización) que están en lugar de otro signo, cosa, realidad o elemento significativo que otorga una unidad intencional de sentido pleno entre uno o varios emisores que transcodifican significados y receptores que destranscodifican los significados que pueblan las cosas, signos, realidades o elementos significativos, entre un horizonte de expectativa y otro de recepción social. De tal manera que, la internalización de un

\footnotetext{
${ }^{4}$ Entendiendo que lenguaje es la capacidad humana de producir signos que están en lugar de otra cosa.
} 
texto puede ser una relación indeterminada de endoculturaciones y simbolizaciones que, en su mayoría, han de ser co-textuales entre el sujeto histórico cultural y el sujeto lírico que habita en el autor y/o lector, ya que todo ser humano viviría y supondría un constructo del modo de la presencia de lo real que se evidencia en un texto, más bien, un endotexto ${ }^{5}$, ya que se manifiesta a través del texto original (tejido o entramado) como expansión antropológica y ontológica del texto, ya que tal como señala Barthes (1987): "el texto es un tejido de citas provenientes de los mil focos de la cultura. [...] el escritor se limita a imitar un gesto siempre anterior, nunca original; el único poder que tiene es el de mezclar las escrituras" (67). Y, ciertamente, que este endotexto se extimisa ${ }^{6}$, conjugando o mezclando las escrituras (del adentro o 'endo') y del afuera (texto) sociocultural, pero que en este caso no se limita a la simple imitación, sino a la asimilación y por lo tanto al constructo del nuevo texto. $\mathrm{Y}$ en tal caso, como es asimilación es entonces endotextualidad y no intertextualidad.

\subsection{Condición de competencia literaria ${ }^{7}$...}

Por lo tanto, la relación endocultural funciona como una capacidad humana y como una condición de competencia literaria, que se concibe entre la relación socio-cultural como experiencia individual y/o colectiva, la enciclopedización o formalización del conocimiento (escolarización), el lenguaje y la competencia literaria propiamente tal. Especialmente esta última que funciona como un

\footnotetext{
${ }^{5}$ Propuesta a propósito de la endoculturación, ya que se manifiesta a través del texto (original: tejido o entramado) como expansión antropológica y ontológica del texto. Pero no se debe confundir con el término usado por Eric Courthès el año 2006 que, más bien fue como una base fractal del texto que le llevaría a una transtextualidad y, este solo hecho, le permitiría reconocer al texto y en el texto su propia capacidad metatextual y esta sería la condición de 'su' endotextualidad.

${ }^{6}$ Aunque según Miller (2010) "la estructura de la extimidad, que se supone capaz de conjugar el afuera y el adentro, y ponernos en condiciones de construir el modo de presencia de lo real en lo simbólico" estaría en discusión todavía.

${ }^{7}$ Esto ya ha sido descripto por mí antes, por lo tanto aquí no nos extenderemos. Para mayor ahondamiento, en el concepto o clave, ver en http://reugra.es/index.php/reugra/article/view/55 Y antes en Rosas: "Competencia literaria”, La nueva novela, Poliexpresión.
} 
diafragma posthistórico que se contrae sobre la endoculturación cuando busca, asimila, recoge la experiencia cultural del productor o receptor, es decir, aquí estaría en juego el adentro: la capacidad humana del lenguaje y sus formas de producción. V. Gr.:

a) Nivel intuitivo $y / o$ significativo (conocimiento previo intuitivo $y / o$ básicamente significativo).

b) Nivel literario (como adquisición sociocultural de la literatura, más bien, el horizonte de la recepción con miras al del mundo de la vida): -sintaxis estable (modos: géneros y estilos) y la -semántica variable (temas, arquetipos, símbolos, metáforas).

c) Nivel lingüístico

1. Factor opositivo (oposición de un signo o significante a otro, ya sea para producir un sonido, significado o un sentido, etc),

2. Factor relativo (es relativo a la semántica y/o significado, idea o concepto; por lo tanto desde y al sujeto)

3. Factor de la negación (es cuando un signo o significante se opone al otro y, según la carga relativa del sujeto, se niega uno o varios de ellos para construir la expresión o expresiones necesarias). (Rosas "Competencia literaria" 127)

Y enseguida, el afuera, como la expresión simbólica o la realización de la lengua, el habla o el diseño retórico en cuestión, pues, "el arte es producido en un mundo artístico no estructurado por ningún relato legitimador, aunque por supuesto, en la conciencia artística queda el conocimiento de los relatos que no tienen más aplicación" (Danto 70). De este modo, mediante esta conciencia artística, existe siempre la posibilidad de que la expresión o manifestación no se haga a través de la lengua, sino que usando su estructura, los relatos que no tienen 
más aplicación, se manifiesten de otro o varios $\operatorname{modos}^{8}$. Obediente, por cierto, a la performancia del sujeto, ya que "la emergencia del sujeto en y por la performancia discursiva engendra un sistema plurisistémico" (Cros 19).

Entonces, cuando esta poliexpresión (Rosas Poliexpresión) se manifiesta, el diafragma funciona contrayéndose en la capacidad humana como producción de la expresión y/o manifestación (a modo de endoculturación) por medio del lenguaje (modo de simbolización) que hace presencia sus realidades o ficcionalidades como mundos posibles. Y que, en tanto crisis, esta como condición poshistórica, se 'des-integra' a modo de poliexpresión, diferente y múltiple, ya como aprehensión del mundo, ya como transliterariedad que otorga valor cualitativo al diseño retórico, como resultado de la producción ya que:

La estructura profunda [del arte posthistórico], [...] es una clase de pluralismo sin precedentes, entendido en términos de una abierta disyunción de medios que, al mismo tiempo, han servido a las correspondientes disyunciones de las motivaciones artísticas y han bloqueado la posibilidad de que el relato de desarrollo progresivo [...] vaya más lejos. (Danto 172)

\section{APROXIMACIÓN A LA OBRA VÍRGENES DEL SOL INN CABARET...}

\subsection{Algunos Antecedentes}

Alexis Figueroa (Concepción, 1956), inició estudios de Filosofía en la U de C en 1973. Allí conoce desde Tomás de Aquino hasta Kant y luego a Nietszche y a Kierkegaard. Y ciertamente, que en aquella época estuvo cerca de Thomas Harris,

8 Como transliterariedad bajtiniana o más bien, todoroviana como 'recurrencias de ciertas propiedades discursivas'. Y muy especialmente como un modo antropológico spangiano del Ser que se manifiesta o deviene luego en los géneros literarios. 
Roberto Henríquez, Carlos Decap. Sobre todo en la aventura que significó para él ‘poesía-performance experimental'. También conoce a Juan Luis Martínez, aduciendo que no es un seguidor de él, pero que es un referente importante, junto a otros, que reafirmaron su quehacer poético experimental.

Figueroa, se ha desempeñado, además, en variados oficios, de guionista de documentales hasta reparador de computadores. Además ha sido editor de importantes revistas literarias de los años ochenta como "La piel de leopardo", "Posdata" y "Tantalia”. Recibe el Premio Municipal de Arte de Concepción el año 2016 por su trayectoria y aporte de más de treinta años a la comuna.

Con su primer libro Vírgenes del Sol Inn Cabaret... obtuvo el Premio "Casa de las Américas" el año 1986. Una última versión fue editada por Cinosargo el 2014. También publicó El laberinto circular y otros poemas (Ediciones de la ventana oval, 1996), Folclórica.doc (Al aire libro, 2003). Asimismo publicó junto al artista visual Claudio Romo en narrativa gráfica, Fragmentos de una biblioteca transparente (LOM, 2008), Informe Tunguska (LOM, 2009). Finis Térrea: apuntes de carretera (LOM, 2014) y Lota 1960: la huelga larga del carbón (Libros de Nébula-Lom, 2014).

Últimamente publicó El cuervo y otros poemas de Edgar Allan Poe, editado por Austrobórea Editores, una selección literaria traducida por él. Y Paprika el japo y otros relatos (2014), por Ajiaco Ediciones.

En los últimos años se ha dedicado a investigar acerca de la gráfica narrativa y sus posibilidades editoriales junto a Claudio Romo, Carlos Valle y Hernán Rodríguez en un proyecto colectivo llamado Libros de Nébula.

\subsubsection{Segunda aproximación: camino al endotexto}

Generalmente es posible vincular cualquier obra con otra u otras obras o manifestaciones artísticas o hechos históricos. A esto, también generalmente, le llamamos intertextualidad, sin embargo, en este trazo teórico, dispondremos de ella, 
mas no como mera abstracción metatextual, sino como una asimilación endocultural, es decir, una asimilación endotextual. Que si bien es cierto es metatextual, también es cierto que su base es la endoculturación y la simbolización como elementos básicos y obligados para producir y/o comprehender el texto literario. De manera que la cuestión estaría centrada en dar con el texto literario o hecho estético como resultado de la endoculturación y simbolización, lo que derivaría en una dialógica de intertextualidad o tejido textual, o sea, el endotexto.

De hecho, para la mayoría de nosotros "todo enunciado posee un autor a quién percibimos en él como tal. Podemos no saber nada acerca del autor real tal como existe [...], pero de todas maneras oímos en el enunciado una única voluntad creadora, una determinada posición a la cual se puede reaccionar dialogando" (Bajtín 257). Lo que hace notar Kristeva aduciendo más bien, a un descubrimiento:

[...] (sic) Un descubrimiento que Bajtín es el primero en introducir en la teoría literaria: todo texto se construye como un mosaico de citas, todo texto es absorción y transformación de otro texto. En el lugar de la noción de intersubjetividad se instala la de intertextualidad, y el lenguaje se lee, por lo menos, como doble. (440-441)

Lo que ciertamente viene a refrendar lo que hay entre el texto primario como acto endocultural y el secundario como potencial de simbolización. Esta sería entonces la relación endotextual o simbólica o acto mismo de escritura/lectura lo que precisamente, Válery, 1944; Jauss, 1978 o Eco, 1993 han llamado Acto9. Todo ello, porque "la obra del espíritu no existe más que en acto. Fuera de este acto, lo que queda no es más que un objeto que no ofrece ninguna relación particular con el espíritu" (Válery 306). A menos claro, que se utilice nuevamente o en relación con el mismo Acto como trasfondo o como relación significativa, especialmente para reificarlo. Y esto es algo que ha descripto Volek (1992) en palabras de Shklovski: "La obra de arte se percibe sobre el trasfondo de otras obras artísticas y

\footnotetext{
${ }^{9}$ Seguramente pensando el concepto aristotélico que dialécticamente deviene en Potencial
} 
por asociación con ellas. La forma de la obra de arte se define por su relación con las formas que la han precedido..." (88)

Y en consecuencia, la intertextualidad no sería otra cosa que un proceso de endoculturación como relación primaria [asimilación con/de ella] y uno de endotextualización o simbolización como secundaria [expresión a través de las formas del texto]. Y para ello podría, eventualmente, relacionarse con la copresencia entre dos o más textos, es decir, eidética y frecuentemente, como la presencia efectiva de un texto en otro. Pero con una condición casi palimséstica que centra su fortaleza en la memoria que recoge, quiéralo o no, la enduculturalidad, en donde la percepción y la acción son parte de ella y no solo del texto, ya que:

La memoria ejerce una presión sobre la percepción, intercala el pasado en el presente, el recuerdo en la sensación, el tiempo en el espacio o el espíritu en la materia. De algún modo, en el punto de contacto entre la materia y la memoria, en el límite o el pliegue entre la percepción y el recuerdo, se ubica la imaginación. Recordar es actualizar un contenido pasado. Para esto, es preciso que ese recuerdo puro, plenamente virtual e impasible, se encarne en una imagen. Esa es la función de la imaginación. (Prósperi 223)

Por lo tanto es posible pensar que las relaciones intertextuales pueden sostenerse sobre la base de la cultura o endoculturalidad como ya lo hemos señalado y tal como lo aproxima González (2012)

Este espacio incluye el entorno, por lo cual puede ser transformado. De ahí la importancia de la intertextualidad, la cual recupera todo el bagaje cultural de un pueblo y a la vez, ayuda al sujeto a decodificar y construir significados complejos.

Pero esta habilidad no puede adquirirse solo por medio de la actuación, sino que el sujeto debe infiltrarse críticamente en los tejidos culturales para tornarse en crítico. (5) 
En consecuencia esta intertextualidad:

Es un tejido de voces que se constituye a partir de la combinación de distintos códigos que ya hemos leído, visto o escuchado en algún momento de nuestra vida. Son códigos que transitan diacrónicamente como fantasmas en las mentalidades de los sujetos que "aparecen" en un aquí y en un ahora, materializándose en un momento sincrónico. (2)

De tal suerte que estaríamos frente a la posibilidad cierta de remitirnos al concepto que aquí estamos esbozando, vale decir:

endoculturalidad + endotextualidad $=$ endotexto

Como así también:

$$
\begin{aligned}
(\text { recordar }+ \text { actualizar }) & =(\text { recepción }+ \text { imagen }) \\
\text { Percepción } & =\text { imaginación } \\
\text { Percepción }+ \text { Endoculturalidad } & =\text { Endotextualidad } \\
\text { Endotexto } & =\text { Poliexpresión }
\end{aligned}
$$

\section{Endotextualización posthistórica en Vírgenes de Sol INN Cabaret...}

La endotextualización posthistórica en Vírgenes del Sol Inn Cabaret... se da precisamente reconociendo la endocultura del autor, el cual ya cuenta con el conocimiento y vivencia del agotamiento espiritual del repertorio de posibilidades heroicas. Sin embargo, no hay que olvidarnos que el receptor también está en el círculo endotextual, ya que está leyendo desde su cultura, su percepción, su escolarización y su capacidad de comprender el mundo literariamente. 
Pues bien, desde esta perspectiva entonces revisamos la obra seleccionada de Figueroa.

En primer lugar, esta como condición de ruptura posthistórica que se produce, básicamente, en la manipulación positiva del afuera, de los elementos del campo de composición, sacudiendo de este modo la petrificación y entropía. Recuérdese que Danto (2006) ha señalado que el arte producido es no estructurado, por lo tanto es la primera situación visible. La que se da en Vírgenes del Sol Inn Cabaret... de modo poliexpresivo, es decir, hay varios modos de expresión; por lo tanto, Figueroa, procedió a romper con esta estructura tradicional poética y, como afirma él mismo, a configurar su obra de otra manera, ya que:

la poesía parecía ser el área de creación lingüística más interesante y libre del planeta ya que podía constituirse en un diseño que abarcara cualquier ámbito de creación, al amparo de su matriz lingüística de operación. Y esto incluía la concretitud de su tipografía, la noción tipográfica del anuncioletrero colgado en la acera. Y así procedí. (Figueroa entrevistado por González)

De este modo entonces, construye un soporte estético experimental, más bien, contra cultural con recortes, dibujos, lengua castellana transgredida por la inglesa, habla, collage, fichas de registro, fotos, anuncios publicitarios, música, películas, menciones a artistas plásticos y escritores, etc.

Figueroa, se transforma entonces, en un sujeto tardo moderno o posmoderno, que en realidad diríamos posthistórico dado que no tiene otra realidad más que el presente poscultural, posbeat, posdictatorial, posficcional como un simulacro de la Historia, una re-presentación de lo impresentable, es decir, como un constructor del presente en crisis. De esta manera recrea su opción estética y ética de afrontar este nuevo mundo. En primer lugar, desde el "Paradigma del Escritor" (nueva portada del libro) que determina de inmediato el tenor del libro y el temple del autor. Y en segundo lugar, desde la dedicatoria: "(yo defino)/ que es 
el escenario en el que hace equilibrios y/ piruetas el payaso disfrazado/ de la televideada humanidad" (Figueroa, Virgenes 69). O sea, esta televideada humanidad está circunscrita a lo que llamábamos la 'caja idiota' y que representó para él una de las objetualidades concretas de la última modernidad (Poo) o agotamiento de los relatos. Y en este contexto, idiotizaba a la humanidad, pero más que eso, sitiaba a la humanidad, ya que en Chile "apareció el Estado de Sitio como la estrategia de supervivencia más adecuada al suspender la política y hacer aparecer la lógica de la guerra" (Lúnecke 97) ${ }^{10}$. Esto ocurre en noviembre del '84 y duró seis meses, sin embargo el toque de queda fue más extenso, la censura en los medios y la agudeza en el conflicto social se extienden hasta el '86 con una violencia política coercitiva, lesiva y destructiva $(18-19 ; 169)$. Aquí la televideada era su forma de resistir en la ciudad concreta, ficcionalizándola al mismo tiempo para poder sobrevivir y por ello es que va adentrándose en este mundo posible poético, pero sin olvidar que en "los prados adyacentes pequeñas tanquetas los / recorren / robots incorruptibles son los guardias de las puertas; / existen haces de partículas secretos, camuflados en / los cercos; / diminutos misiles enterados en el pasto" (Figueroa, Virgenes 14). Y esta manera de endotextualizar nos va dando la referencia necesaria sobre el momento real que se vive en la ciudad, el cual no puede ser denunciado ni descrito por la permanente y omnípoda presencia de la dictadura, pero que sí se puede comunicar a los otros con juegos lingüísticos, fotomontajes, collages, dibujos y relatos que se creen extintos porque no se correlacionan directamente con la realidad, sin embargo lo hacen cada vez que produce una poliexpresión y a través del diafragma poshistórico, se complementa con el receptor, quien no solo lee bien esta circunstancia, sino que la traduce para sí y para los otros. Por lo tanto aquello que se creía terminado como los relatos, la Historia, en realidad se encubre de modo endocultural a través de un endotexto. Por esto es que la poesía, mejor dicho, el poema, no es estructurado como se esperaría que lo fuera, sino que es un de(s)constructo que mimetiza y ficcionaliza, regulando

${ }^{10}$ Se puede leer en línea en http://www.memoriachilena.cl/archivos2/pdfs/MC0033342.pdf y en http://www.memoriachilena.cl/602/w3-article-92408.html 
la verosimilitud del metarrelato, mediante esta poliexpresión que es más bien espe(cta)cular y éxtima; pero en abierta oposición a la 'máquina gigantesca en proceso de petrificación:

Welcome to the TV,

welcome to the machine.

Vien benidos al salon del invierno luminoso, (sic)

vien benidos al túnel del amor en las muchachas de las luces de neón.

Hoy tendremos cajas de cristal sobre la pista,

(Vien) benidos al lugar de las luces calcinantes, welcome to the machine.

(Figueroa, Virgenes del Sol 12)

En otro ámbito, hay que destacar entonces que Figueroa, prueba la existencia de este metarrelato, de resistencia si se quiere; con un conocimiento filosófico, cultural e ideológico que ya tenía y que podía reutilizar para seguir reflexionando y denunciando. Y sobre todo, oponiéndose a este nuevo modo de vivir: la decadencia de la modernidad, puesto que la luz de la razón ha caído en desgracia y prueba de ello es la dictadura. Por lo tanto la manera de extimizar la resistencia, tanto personal como colectivamente es mediante la percepción, endoculturalidad y la poliexpresión, ya que decide mantener el metarrelato y no creerle a la supuesta posmodernidad y por lo tanto la mejor forma de hacerlo es algo así como la teoría del espejo, es decir, especular la realidad (endotextualizarla como espectáculo):

(penetrad por las puertas de colores, entrad sin miedo, decidíos, que detrás ellas espéranles temblando, dispuestas a mojarlos con su lluvia, a llevarles por la noche en la balsa de sus cuerpos, a extraviarles como un pájaro en plena tempestad). (18) 
O bien en la siguiente estrofa:

Motivos para preocuparse no hay ninguno

(abrid la puerta roja)

ved, estáis seguros:

hay lasers en el techo,

los prados adyacentes pequeñas tanquetas los recorren, robots incorruptibles son los guardias de las puertas.

Existen haces de partículas secretos, camuflados en los cercos, diminutos misiles enterrados, ciertos dragones electrónicos equipados con agujas radioactivas, que no os atacaran, pero si es otro el que ... (19)

Por lo tanto, denunciar la realidad fragmentada y endotextualizada es para sostener y reafirmar ese metarrelato que se llama nación, patria, ciudadanía que ha sido degrada lo mismo que la ciudad concreta y los espacios, dado que dependerá del visitante o los visitantes que lleguen allí en un estado de excepción del país. Pero también del prostíbulo que no tuvo mayor restricción en la época, como en todas las dictaduras en todo caso. Lo que podemos leer apenas se inicia la lectura en la dedicatoria: "Y a la gente de mi patria, pero nunca para toda, pero nunca para toda" (5). Y ciertamente en "Inicio General O" (11) en donde se presenta cada relato como si fuera uno o algo nuevo: "en la que se existe vigilado por la Donald Duck Police" (26). 


\section{A MODO DE TRANSICIÓN (INN)CONCLUSA}

De tal manera que los distintos medios (o códigos) de producción en Virgenes del Sol Inn Cabaret... están cruzados por la experiencia cultural (endocultura y nuevas experiencias en la nueva ciudad) del autor y su modo de expresar (endotexto y transcodificación). Por lo tanto, Figueroa, procedió, como afirmó él mismo, a configurar su obra de otra manera. De este modo, entonces, construye un soporte estético antipoético, más bien, contra cultural.

De modo que Figueroa se transforma en un sujeto posficcional, como un simulacro de la Historia, 'una re-presentación de lo im-presentable', es decir, como un constructor del presente de la 'última modernidad' como nueva ciudad, como una condición posthistórica ficcional que se levanta entre agotamiento, petrificación y entropía endotextualmente: "(yo defino)/ que es el escenario en el que hace equilibrios y/ piruetas el payaso disfrazado/ de la televideada humanidad" (69).

Por lo tanto, denunciar la realidad fragmentada y endotextualizada es para sostener y reafirmar ese metarrelato que se llama nación, patria, ciudadanía que ha sido degrada lo mismo que la ciudad concreta. Y por esta razón hubo de ficcionalizarla en una nueva forma: el endotexto, como una fuerte manifestación poshistórica de aquello que aparentemente era indiscernibilidad e incertidumbre.

En suma, Virgenes del Sol inn Cabaret... es un relato heroico que quiebra la petrificación y entropía con esta nueva máquina textual, superpoderosa de construcción de realidades televideadas, gracias a la endoculturación y a la competencia literaria, tanto del autor como del receptor, "en la que se existe vigilado por la Donald Duck Police". 


\section{Bibliografía}

Adorno, T. W. Teoría Estética. Madrid: Taurus, 1971. Impreso.

Albamonte, M. A. et al. "La importancia de la simbolizacion en los procesos de aprendizaje". Revista de la Sociedad Española de Psiquiatría y Psicoterapia del Niño y del Adolescente. Cuadernos de psiquiatria y psicoterapia infantil. V Congreso nacional: "los trastornos de aprendizaje". (Octubre de 1991): 109-135.

Barthes, R. El susurro del lenguaje. Barcelona: Paidós, 1987. Impreso.

Bajtín, M. Problemas de la poética de Dostoievski. México: FCE, 1986. Impreso.

Brierley, D. “Artes, emociones y creatividad". Informe "Artes y emociones que potencian la creatividad”. Santander, España: Fundación Botín. 2014. Impreso.

Cros, Edmond. El sujeto cultural: sociocrítica y psicoanálisis. Medellín: Fondo Editorial Universidad Eafit. 2003. Impreso.

Danto, Arthur. Después del fin del arte. El arte contemporáneo y el linde la historia. Buenos.Aires: Paidós. 2006. Impreso.

Eco, Umberto. Lector in fabula. La cooperación interpretativa en el texto narrativo. Barcelona: Lumen, 1993. Impreso.

Figueroa, Alexis: "Soy un accidente insectívoro". Letras.mysite.com. Proyecto Patrimonio. 2004. Web. 17 oct. 2018. . Virgenes del Sol Inn Cabaret. Ed. Papeles del Andicán - Cuadernos Sur, 1986.

Harris, Marvin. Antropología cultural. Madrid: Alianza Editorial, S. A. 2001. Impreso.

Jauss, Hans Robert. Pour une esthétique de la réception. Paris: Gallimard, 1978. Impreso.

Kristeva, Julia. "Bajtín, La palabra, el diálogo y la novela". En Critique No 239, (abril 1967): 440-441. Impreso. 
. "La sémiotique, science critique et/ou critique de la science ", en Semeiotiké: recherches pour une sémanalyse. París: Editions du Seuil, Collection Tel Quel. 1969. Impreso.

López-Dominguez, V. "Reflexiones sobre la historia para "tiempos posthistóricos". Logos. Anales del Seminario de Metafísica. Núm. 1. Servicio de Publicaciones. Universidad Complutense. Madrid. (1999): 305-321. Impreso.

Lúnecke Reyes, Graciela Alejandra. Memoria Chilena. Centro de Recursos Digitales. Biblioteca Nacional de Chile. Violencia Política (Violencia Política en Chile. 1983-1986). Santiago de Chile: Fundación Documentación y Archivo de la Vicaría de la Solidaridad, 2000 . Web. 21 de marzo. 2019.

Poo, Ximena. "La última modernidad de Alexis Figueroa". Letras.mysite.com. Proyecto Patrimonio. Diario La Época, martes 25 de junio de 1996. Web. 17 de oct. 2018.

Prósperi, Germán Osvaldo. "El texto como palimpsesto. Reflexiones en torno a la lectura literaria”. Revista chilena de Literatura. Número 93 (Noviembre. 2016): 215-234. Impreso.

Rosas Godoy, J. “Competencia literaria y poliexpresión: una innovación en la transmisión y/o enseñanza de la literatura desde la nueva novela de Juan Luis Martínez". Revista de Educación de la Universidad de Granada (2016) 23: 119-131. . La nueva novela: aproximaciones a una estética de los nuevos tiempos. Saarbrücken, Deutschland. AV Akedemikerverlag GmhB \& Co. KG. 2012. Impreso. . POLIEXPRESION o la des-integración de las formas en / desde La nueva novela de Juan Luis Martínez. Buenos Aires - Argentina / Los Angeles- USA.: Editorial Argus-a. 2016. Impreso. 
CATEDRAL Tomada: Revista de crítica literaria latinoamericana / Journal of Latin American Literary Criticism Aproximación a Vírgenes del Sol Inn Cabaret...: una condición Posthistórica y de Competencia Literaria

Paul Valéry. «Première leçon du cours de poétique» (1937). Leçon inaugurale du cours de poétique du Collège de France, in Variété V, Nrf, Gallimard, (1944): 295-322. Impreso.

Vásquez Rocca, Adolfo. "Arthur C. Danto: Simulacros y posthistoria” [1 $1^{\mathrm{a}}$ parte $]$.

Homines.com. Portal de arte y cultura. 2016. Web. Oct. 2017.

Volek, Emil. Antología del formalismo ruso y el grupo de Bajtin. Madrid: Editorial Fundamentos.1992. Impreso. 